\title{
Atopy, lung function and bronchial responsiveness in symptom-free paediatric asthma patients
}

\author{
W. Gruber, E. Eber, B. Steinbrugger, M. Modl, E. Weinhandl, M.S. Zach
}

\begin{abstract}
Atopy, lung function and bronchial responsiveness in symptom-free paediatric asthma patients. W. Gruber, E. Eber, B. Steinbrugger, M. Modl, E. Weinhandl, M.S. Zach. (C)ERS Journals Ltd 1997.

ABSTRACT: In adolescence, some paediatric asthma patients will become symptom-free and require no further treatment. There is little information on the atopic status, lung function and bronchial responsiveness of these patients.

Symptom-free asthma patients $(n=118)$ aged 7.7-19.2 yrs, were evaluated 1 year after termination of therapy. Bronchial asthma had previously been diagnosed on the basis of recurrent wheezing episodes. Atopic status was assessed by skin-prick testing. Baseline lung function was measured by spirometry, flow-volume curve and plethysmography. Bronchial responsiveness was assessed nonpharmacologically by cold dry air challenge.

Eighty one patients had at least one positive skin test result, and the remaining 37 were defined as nonatopic. In atopic subjects, the prevalence of bronchial hyperresponsiveness was significantly higher than in nonatopic patients (41 out of 81 versus 7 out of $37 ; p=0.001$ ). Atopic subjects showed a significantly lower maximal expiratory flow at $25 \%$ remaining vital capacity $(p<0.05)$ and a higher residual volume $(\mathbf{p}<0.05)$ than nonatopic subjects. Nonatopic subjects were significantly younger than atopic patients $(p<0.01)$.

These symptom- and medication-free paediatric and adolescent asthma patients could, thus, be divided into two groups: 1) atopic subjects with a tendency towards bronchial hyperresponsiveness; and 2) nonatopic subjects with better lung function and normal bronchial responsiveness. In view of the increased understanding of the epidemiology of early childhood wheezing, these findings support the concept of different pathogenic mechanisms underlying wheezing episodes in early childhood.

Eur Respir J 1997; 10: 1041-1045.
\end{abstract}

Respiratory and Allergic Disease Division, Paediatric Dept, University of Graz, Austria.

Correspondence: M.S. Zach

Respiratory and Allergic Disease Division Paediatric Dept

University of Graz

Univ. Klinik für Kinder- und Jugendheilkunde

Auenbruggerplatz 30

A-8036 Graz

Austria

\section{Keywords: Asthma}

atopy

bronchial responsiveness

children

lung function

natural history

Received: August 121996

Accepted after revision January 281997
In adolescence, some paediatric asthma patients become symptom-free and require no further antiasthma treatment. Studies that have focused on the natural history of asthma from childhood to adulthood indicate that 16$57 \%$ of paediatric asthma patients go into a clinically defined remission [1-8]. One would assume that such a remission should be associated with normalized lung function. Indeed, some studies have demonstrated normal lung function values in asthma patients without current respiratory symptoms $[9,10]$; others, however, have documented persisting functional abnormalities in currently symptom-free patients $[11,12]$.

Bronchial hyperresponsiveness (BHR) is considered an important feature of the asthma syndrome [13, 14]. Only a few studies on the outcome of childhood asthma have subsequently evaluated bronchial responsiveness (BR) in symptom-free adolescents and adults. These studies have produced widely differing results, with the prevalence of BHR ranging 7-63\% [4-6, 9, 10, 15, 16]. All these studies used pharmacological challenges for assessing BR. However, nonpharmacological challenges, i.e. provocations that use physical stimuli, might be more specific for indicating bronchial asthma [17-19]. Thus, it would be of special interest to evaluate BR in symptom-free paediatric and adolescent asthma patients by a nonpharmacological challenge.

Atopy, indicated by skin reactivity to common allergens, has a special relationship to the development, the prevalence, and the severity of bronchial asthma [20-23]. Several studies have documented that atopy occurs in close association with BHR, and this was found both for asthma patients and random population samples [20, 24-31]. So far, however, the association of atopy and BR has not been studied in symptom- and medicationfree paediatric and adolescent asthma patients.

In the present study, we therefore assessed atopic status, lung function and BR in a group of paediatric and adolescent patients who were in clinical remission of their asthma.

Materials and methods

\section{Subjects}

This investigation was part of an ongoing epidemiological study, evaluating asthma patients at the local paediatric respiratory centre, who have become free of 
asthma symptoms and have stopped taking antiasthma medication for 1 year. Of a total of 132 patients meeting this definition, 118 were recruited successively from 1989 to 1993; this group consisted of 45 females (38\%) and 73 males $(62 \%)$, with a mean \pm SD age of $13.0 \pm 2.6$ yrs (range 7.7-19.2 yrs). All patients had previously been diagnosed as having bronchial asthma on the basis of clinical criteria $[13,14]$. Thus, this diagnosis was based mainly on the clinical observation of recurrent episodes of bronchial obstruction responsive to bronchodilators and separated by symptom-free intervals of varying duration. Other chronic obstructive airway disorders had been excluded by relevant investigations in all patients. When necessary, clinical data were obtained retrospectively by reviewing the files of the out-patient clinic.

Informed consent for this investigation was obtained both from the patient and the parents.

\section{Atopic status}

The atopic status was assessed by skin-prick testing with 14 common environmental allergens (ALK, Copenhagen, Denmark), including house dust mites (Dermatophagoides pteronyssinus, Dermatophagoides farinae), weed pollen (mugwort, ragweed, plantain), tree pollen (birch, hazel, alder), grass pollen (grass mix, rye), moulds (Alternaria alternata, Cladosporium herbarum), and animal dander (cat, dog). Skin testing included a positive histamine and a negative saline control, and was performed by pricking through the droplets of allergen, using a standard $1 \mathrm{~mm}$ prick lancet (ALK, Copenhagen, Denmark). The maximum wheal diameter was measured after 15 min. A test was regarded as positive when producing a wheal of $\geq 3 \mathrm{~mm}$ [32]. A positive response to histamine and a negative response to the diluent were considered prerequisites for accepting the test result as valid. The subject was defined as atopic when there was a positive response to one or more of the tested allergens.

\section{Baseline lung function}

Measurements were performed in accordance with standardized guidelines [33]. Forced vital capacity (FVC), forced expiratory volume in one second (FEV1), and forced expiratory flow during the middle half of the FVC (FEF25-75) were measured with a water-filled spirometer (Spiro-Junior; Jaeger, Würzburg, Germany). Total lung capacity (TLC), residual volume (RV), and airway resistance (Raw) were measured in a constant volume, whole-body plethysmograph (Body-Test; Jaeger) according to the methods of DuBors and co-workers [34, 35]. A maximal expiratory flow-volume (MEFV) curve was recorded on a pneumotachograph spirometer (BodyTest; Jaeger). Maximal expiratory flow at 50\% (MEF50) and at $25 \%$ remaining FVC (MEF25) were measured from the MEFV curve. Results were expressed as percentage of predicted normal, based on relevant reference standards [36].

\section{Bronchial responsiveness}

BR was assessed nonpharmacologically by a singlestep cold dry air challenge (CACh), according to an established protocol $[37,38]$. After measurement of the prechallenge FEV1, CACh consisted of a $4 \mathrm{~min}$ isocapnic hyperventilation of absolutely dry, $-10^{\circ} \mathrm{C}$ air at $75 \%$ of maximal voluntary ventilation. Cold dry air was produced by a commercially available heat exchanger (RHES; Jaeger). Three minutes after termination of the challenge, FEV1 was measured again. The change in FEV1 $(\triangle \mathrm{FEV} 1)$ from the baseline to the postchallenge measurement was expressed in percentage baseline FEV1. For this method, a $\triangle \mathrm{FEV} 1$ of minus $9 \%$ or more defines BHR [37].

\section{Statistical analysis}

Data in contingency tables were analysed by the Chisquared test. Analysis of continuous data was performed using the one-way analysis of variance (ANOVA). A pvalue of 0.05 or less was taken as indicating statistical significance.

\section{Results}

\section{Demographic data, atopic status}

Of the 118 children and adolescents, $81(69 \%)$ had one or more positive skin test reaction(s), and 37 (31\%) remained negative to all tested allergens. This proportion of nonatopic subjects is significantly higher than the proportion of nonatopic asthma patients in the local out-patient clinic, which typically ranges $12-14 \%$ and is presently $13 \%$ of a total of 1,230 patients.

A comparison of the atopic and nonatopic groups revealed the following differences. The atopic group included more males than females $(55 / 26)$, whereas the distribution of sexes in the nonatopic group (18/19) appeared roughly equal, and this difference reached statistical significance $(\mathrm{p}<0.05)$. Currently, the male/female ratio in the patients of the local outpatient clinic is 1.9/1.0; thus, the sex ratio in the atopic group reflects that in our out-patient population. Age at the study was lower in the nonatopic group (mean \pm SD $12.1 \pm 2.6 \mathrm{yrs}$; range 7.7-19.2 yrs) than in the atopic group (13.4 \pm 2.5 yrs; range 8.8-18.4 yrs), and this difference was statistically significant $(\mathrm{p}<0.01)$. When comparing the prevalence of atopy in the younger children $(<13$ yrs $)$ with that in the adolescents ( $>13$ yrs $)$, there was a tendency towards less atopic patients (63 versus 74\%), which, however, remained nonsignificant.

\section{Baseline lung function}

Baseline lung function parameters are presented in table 1 . In the atopic group, MEF25 was significantly lower and RV was significantly higher than in the nonatopic group, whereas the other parameters did not differ significantly.

\section{Bronchial responsiveness}

A total of 48 children ( $41 \%$ ) showed BHR to CACh. The percentage of subjects with BHR was significantly 
Table 1. - Baseline lung function parameters

\begin{tabular}{llccc}
\hline & & Atopic & Nonatopic & p-value \\
\hline FVC & $\%$ pred & $105 \pm 11$ & $102 \pm 11$ & NS \\
FEV1 & $\%$ pred & $100 \pm 12$ & $99 \pm 10$ & NS \\
FEF25-75 & $\%$ pred & $93 \pm 22$ & $94 \pm 22$ & NS \\
MEF50 & $\%$ pred & $105 \pm 26$ & $106 \pm 26$ & NS \\
MEF25 & $\%$ pred & $99 \pm 34$ & $114 \pm 41$ & $<0.05$ \\
RV & $\%$ pred & $118 \pm 32$ & $105 \pm 27$ & $<0.05$ \\
TLC & $\%$ pred & $106 \pm 13$ & $101 \pm 12$ & NS \\
RV/TLC & $\%$ pred & $26 \pm 5$ & $25 \pm 5$ & NS \\
Raw & $\%$ pred & $153 \pm 51$ & $147 \pm 49$ & NS \\
\hline
\end{tabular}

Values are presented as mean \pm SD. FVC: forced vital capacity; FEV1: forced expiratory volume in one second; FEF25-75: forced expiratory flow during the middle half of the FVC; MEF50 and MEF25: maximal expiratory flow at 50\% and 25\% remaining FVC; RV: residual volume; TLC: total lung capacity; Raw: airway resistance; \% pred: percentage of predicted value; NS: nonsignificant.

higher in the atopic group than in the nonatopic group (52 versus $19 \% ; \mathrm{p}=0.001$ ), and the mean CACh-induced change of FEV1 was significantly higher in the atopic than in the nonatopic subjects $(-13.0 \pm 13.5 \%$ vs $-4.9 \pm 4.9 \%$; $\mathrm{p}<0.001)$. When comparing the prevalence of BHR in the younger children $(<13$ yrs $)$ with that in the adolescents $(>13 \mathrm{yrs})$, there was a statistically significant difference (23 vs 57\%; $\mathrm{p}<0.001)$.

\section{Discussion}

The findings of this study demonstrate that: 1) approximately $40 \%$ of the symptom- and medication-free paediatric and adolescent asthma patients of this centre demonstrate BHR to $\mathrm{CACh}$; 2) atopic subjects reach clinical remission less often and later than nonatopic patients; and 3) in contrast to nonatopic patients, atopic subjects tend towards discrete small airway dysfunction and maintained BHR. In combination with other recent epidemiological findings, this study raises serious questions regarding the clinical identification and treatment of bronchial asthma in paediatric patients.

Several previous studies have evaluated the prevalence of BHR in asthma patients who had reached a clinically defined remission [4-6, 9, 10, 15, 16]. MARTIN et al. [9] demonstrated that $60 \%$ of subjects with a history of wheezing during childhood had an increased BR at the age of $21 \mathrm{yrs}$. A follow-up study at the age of 28 yrs revealed BHR in $30 \%$ of the asymptomatic subjects; this no longer differed significantly from the control group [10]. GERRITSEN et al. [4] found a decrease in the prevalence of BHR from $82 \%$ in childhood to $29 \%$ in adulthood. GodDEN et al. [16] investigated the outcome of childhood asthma after $25 \mathrm{yrs}$ and found an increased BR in $42 \%$ of the asymptomatic patients. Boulet et al. [15] demonstrated that $63 \%$ of symptomand medication-free adults with a history of asthma had an increased BR. Two further studies re-examined paediatric asthma patients in adulthood and found BHR in $20 \%$ of the asymptomatic subjects $[5,6]$. These widely differing results might be due to marked differences in the clinical definition of a remission, in the recruitment of subjects, and in the sensitivity of the provocation methods used.
In the present study, $41 \%$ of all patients investigated showed persisting BHR to CACh. This prevalence of BHR to a nonpharmacological stimulus cannot be compared directly to the results of the above-quoted studies, as most of those were performed exclusively by using pharmacological provocations. Studies comparing nonpharmacological and pharmacological stimuli for identifying BHR in paediatric patients suggest that CACh is less sensitive but more specific for indicating asthma than conventional pharmacological challenges $[17,39]$. The $41 \%$ prevalence of BHR to CACh found in the present study should, thus, be interpreted from the perspective that this technique defines fewer subjects as hyperreactive than pharmacological methods. However, the asthma patient population of a specialized paediatric respiratory centre might not include the milder end of the paediatric asthma spectrum; thus, the high prevalence of BHR found in this study might, at least in part, also be explained by the selection of the patients investigated. From a more general perspective, however, both pharmacological and nonpharmacological investigations seem to agree in finding a high prevalence of persisting BHR in symptom- and medication-free asthma patients. Whether BHR has a prognostic significance in these patients, indicating those subjects who will experience a later relapse of their symptoms, remains to be determined in future long-term studies.

Several studies have examined the relationship between atopy and BR in random population samples and in asthma patients $[15,20,24-31,40]$. Some authors have succeeded in demonstrating association between atopy and BHR in subjects with current asthma and other respiratory symptoms [24-31], while others have not found such an association [40]. Few data are available on the relationship between atopy and BR in symptom- and medication-free asthma patients. In the study by BoulET et al. [15], adult asthma subjects, reporting no symptoms or medication requirement for at least $2 \mathrm{yrs}$, showed no correlation between BR to methacholine and the number of positive skin test results. The present study, however, demonstrates that the presence of atopy is significantly associated with an increased prevalence of BHR to CACh.

Some differences between these two results might be explained by the different populations investigated, the different study designs, and the different provocation methods used. It has been suggested that nonpharmacological challenges might have more relevance for the clinical course of bronchial asthma than pharmacological provocations $[18,19,37,38]$; thus, the result of the present study might have some prognostic significance. The finding that the contribution of atopic patients to the present study population was much smaller than might have been expected from their representation in the local asthma out-patient clinic, indicates that there is a much weaker tendency to go into remission for these atopic subjects than for the nonatopic wheezers. In a more general sense, the findings of the present study are in agreement with the results of those epidemiological studies that demonstrated a correlation between the atopic status of children and the presence or the degree of BR [25-27, 29, 30].

In the present study, the atopic group differed from the nonatopic subjects in having a higher $\mathrm{RV}$ and a 
lower MEF25; differences between groups, however, were small and mean values for both groups remained in the normal range. In other studies, signs of persisting small airway obstruction and hyperinflation were found in symptom-free asthma patients, suggesting that, even when asthma symptoms have disappeared, asymptomatic airway obstruction may persist [11, 12]. The Melbourne follow-up studies also evaluated lung function in young adults who had wheezed in childhood $[9,10]$; these authors found that the lung function of subjects who had minor wheeze in childhood but who had been free of wheeze for at least 3 yrs was indistinguishable from that of control subjects. Again, subject selection, especially differences in asthma severity, might account for the discrepancy between these results. Furthermore, the Melbourne studies could have included many nonatopic wheezers, and these might have biased the group outcome towards normal lung functions. When these patients were analysed regarding their atopic status, a clear correlation between atopy and asthma severity became evident [22].

With a prospective population-based study of infants enrolled as newborns, MARTINEZ and co-workers [41, 42] significantly contributed to our present understanding of the epidemiological implications of early childhood wheezing. These authors found that children who still had symptoms at 6 yrs of age were more likely to have atopic asthma than children with transient wheezing occurring before the age of 3 yrs. The latter group had diminished airway function both in the first year of life and at the age of 6 yrs. These findings suggest that genetically-determined small airways can predispose infants to wheeze in association with viral infections, but, as airways increase in size with age, they will eventually become free of wheeze. The findings of the present study are in agreement with these results and the evolving epidemiological concept. Some nonatopic children with small airways, who wheezed repeatedly with viral infections, might be included in the nonatopic group of the present study population. After becoming free of symptoms, they had reached a clinically defined remission of their wheezing illness earlier than the atopic asthma patients, and their (probably unnecessary) medication was stopped. As their airways had grown, their lung functions had normalized; furthermore, their BR might have been normal all along. This group of patients, who eventually became free of wheeze, might account for the comparatively high remission rate of nonatopic patients that was found in the present study. This interpretation of results, however, remains a hypothesis that can only be substantiated by further prospective longterm epidemiological investigations. As a likely hypothesis, however, it raises several important questions.

The first question is one of definition and classification: is "nonatopic asthma" an existing entity in the paediatric asthma spectrum or not? The second question raises the issue of antiasthma medication prescribed to infants and children with recurrent wheezing. One can speculate that the term "nonatopic asthma" describes a heterogeneous group, dominated by recurrently wheezing infants and toddlers with genetically-determined anatomical predispositions, but possibly also including other undefined nonatopic disorders. In infancy and early childhood, this group might be clinically indistinguishable from patients with atopic asthma. In order to counterbalance frequently occurring undertreatment of childhood asthma, it has been suggested that the majority of paediatric wheezing disorders should be regarded as bronchial asthma [43], and many centres have now adhered to this concept for more than a decade. As illustrated by the present study, however, this clinical policy of translating recurrent wheezing in the first years of life into the diagnosis of asthma is no longer acceptable, as it might frequently result in unnecessary pharmacological therapy and exaggerated environmental control measures.

In conclusion, this study evaluated a group of paediatric and adolescent patients who had previously been defined as having bronchial asthma on the basis of recurrent wheezing episodes, and who had later become free of symptoms; atopic subjects reached remission later and showed a tendency towards bronchial hyperresponsiveness. In combination with other recent publications, these results suggest that milder forms of recurrent wheezing in infancy and childhood might not suffice for commencing long-term antiasthma treatment. Clinical symptoms alone do not make it possible to predict the future clinical course. The patient could go on to have atopic asthma, that should be treated as early as possible; alternatively, the patient could eventually grow out of his/her wheezing illness without developing atopy or bronchial hyperresponsiveness, and, thus, should not receive long-term treatment. Additional diagnostic criteria that can aid in solving this dilemma are urgently needed.

\section{References}

1. Blair H. Natural history of childhood asthma: 20 year follow-up. Arch Dis Child 1977; 52: 613-619.

2. Martin AJ, McLennan LA, Landau LI, Phelan PD. The natural history of childhood asthma to adult life. $\mathrm{Br}$ Med $J$ 1980; 280: 1397-1400.

3. Kelly WJW, Hudson I, Phelan PD, Pain MCF, Olinsky A. Childhood asthma in adult life: a further study at 28 years of age. Br Med J 1987; 294: 1059-1062.

4. Gerritsen J, Koeter GH, Postma DS, Schouten JP, Knol K. Prognosis of asthma from childhood to adulthood. Am Rev Respir Dis 1989; 140: 1325-1330.

5. Jönsson JA, Boe J. Asthma as a child: symptom-free as an adult? Ann Allergy 1992; 69: 300-302.

6. Kokkonen J, Linna O. The state of childhood asthma in young adulthood. Eur Respir J 1993; 6: 657-661.

7. Kjellman B, Hesselmar B. Prognosis of asthma in children: a cohort study into adulthood. Acta Paediatr 1994; 83: 854-861.

8. Oswald H, Phelan PD, Lanigan A, Hibbert M, Bowes G, Olinsky A. Outcome of childhood asthma in midadult life. BMJ 1994; 309: 95-96.

9. Martin AJ,.Landau LI, Phelan PD. Lung function in young adults who had asthma in childhood. Am Rev Respir Dis 1980; 122: 609-616.

10. Kelly WJW, Hudson I, Raven J, Phelan PD, Pain MCF, Olinsky A. Childhood asthma and adult lung function. Am Rev Respir Dis 1988; 138: 26-30.

11. Cooper DM, Cutz E, Levison H. Occult pulmonary abnormalities in asymptomatic asthmatic children. Chest 1977; 71: 361-365. 
12. Kerrebjin KF, Fioole AC, Bentveld RDW. Lung function in asthmatic children after a year or more without symptoms or treatment. Br Med J 1978; 1: 886-888.

13. American Thoracic Society. Standards for the diagnosis and care of patients with chronic obstructive pulmonary disease (COPD) and asthma. Am Rev Respir Dis 1987; 136: 225-244.

14. National Heart, Lung and Blood Institute, National Institutes of Health, Bethesda, Maryland 20892. International consensus report on diagnosis and treatment of asthma. Eur Respir J 1992; 5: 601-641.

15. Boulet LP, Turcotte H, Brochu A. Persistence of airway obstruction and hyperresponsiveness in subjects with asthma remission. Chest 1994; 105: 1024-1031.

16. Godden DJ, Ross S, Abdalla M, et al. Outcome of wheeze in childhood: symptoms and pulmonary function 25 years later. Am J Respir Crit Care Med 1994; 149: 106-112.

17. Galdes-Sebaldt M, McLaughlin FJ, Levison H. Comparison of cold air, ultrasonic mist, and methacholine inhalations as tests of bronchial reactivity in normal and asthmatic children. J Pediatr 1985; 107: 526-530.

18. Anderson SD, Smith CM. Osmotic challenges in the assessment of bronchial hyperresponsiveness. Am Rev Respir Dis 1991; 143: S43-S46.

19. Zach M. Cold dry air challenge for measuring bronchial responsiveness: where do we stand? Pediatr Pulmonol 1995; 19: 323-325.

20. Cockcroft DW, Murdock KY, Berscheid BA. Relationship between atopy and bronchial responsiveness to histamine in a random population. Ann Allergy 1984; 53: 26-29.

21. Zimmerman B, Feanny S, Reisman J, et al. Allergy in asthma. I. The dose relationship of allergy to severity of childhood asthma. J Allergy Clin Immunol 1988; 81: 63-70.

22. Kelly WJW, Hudson I, Phelan PD, Pain MCF, Olinsky A. Atopy in subjects with asthma followed to the age of 28 years. J Allergy Clin Immunol 1990; 85: 548-557.

23. Van Asperen PP, Mukhi A. Role of atopy in the natural history of wheeze and bronchial hyperresponsiveness in childhood. Pediatr Allergy Immunol 1994; 5: 178-183.

24. Cockcroft DW, Killian DN, Mellon JJA, Hargreave FE. Bronchial reactivity to inhaled histamine: a method and clinical survey. Clin Allergy 1977; 7: 235-243.

25. Witt C, Stuckey MS, Woolcock AJ, Dawkins RL. Positive allergy prick tests associated with bronchial histamine responsiveness in an unselected population. $J$ Allergy Clin Immunol 1986; 77: 698-702.

26. Martinez FD, Antognoni G, Macri F, et al. Parental smoking enhances bronchial responsiveness in nine year old children. Am Rev Respir Dis 1988; 138: 518-523.

27. Clifford RD, Radford M, Howell JB, Holgate ST. Prevalence of atopy and range of bronchial response to methacholine in 7 and 11 year old schoolchildren. Arch Dis Child 1989; 64: 1126-1132.

28. Clifford RD, Howell JB, Radford M, Holgate ST. Associations between respiratory symptoms, bronchial response to methacholine, and atopy in two age groups of schoolchildren. Arch Dis Child 1989; 64: 1133-1139.
29. Backer V, Ulrik CS, Hansen KK, Laursen EM, Dirksen A, Bach-Mortensen N. Atopy and bronchial responsiveness in a random population sample of 527 children and adolescents. Ann Allergy 1992; 69: 116-122.

30. Peat JK, Salome CM, Woolcock AJ. Factors associated with bronchial hyperresponsiveness in Australian adults and children. Eur Respir J 1992; 5: 921-929.

31. Roorda RJ, Gerritsen J, van Aalderen WMC, Knol K. Skin reactivity and eosinophil count in relation to the outcome of childhood asthma. Eur Respir J 1993; 6: 509-516.

32. Dreborg S, ed. Skin tests used in type I allergy testing. Position paper of the European Academy of Allergology and Clinical Immunology. Allergy 1989; 44 (Suppl. 10): 27-28.

33. Quanjer PH, Tammeling GJ, Cotes JE, Pederson OF, Peslin R, Yernault J-C. Lung volumes and forced ventilatory flows. Report working party standardization of lung function tests. European Coal and Steel Community. Official statement of the European Respiratory Society. Eur Respir J 1993; 6, Suppl.16: S5-S40.

34. DuBois AB, Botelho SY, Bedell GN, Marshall R, Comroe JH. A rapid plethysmographic method for measuring thoracic gas volumes: a comparison with a nitrogen wash-out method for measuring functional residual capacity in normal subjects. J Clin Invest 1956; 35: 322-326.

35. DuBois AB, Botelho SY, Comroe JH. A new method for measuring airway resistance in man using a body plethysmograph: values in normal subjects and in patients with respiratory disease. J Clin Invest 1956; 35: 327-335.

36. Hibbert ME, Lannigan A, Landau LI, Phelan PD. Lung function values from a longitudinal study of healthy children and adolescents. Pediatr Pulmonol 1989; 7: 101-109.

37. Zach M, Polgar G, Kump H, Kroisel P. Cold air challenge of airway hyperreactivity in children: practical application and theoretical aspects. Pediatr Res 1984; 18: 469-478.

38. Zach M, Polgar G. Cold air challenge of airway hyperreactivity in children: dose-response interrelation with a reaction plateau. J Allergy Clin Immunol 1987; 80: 9-17.

39. Steinbrugger B, Eber E, Modl M, Weinhandl E, Zach MS. A comparison of a single-step, cold, dry air challenge and a routine histamine provocation for the assessment of bronchial responsiveness. Chest 1995; 108: 741-745.

40. Bryant DH, Burns MW. The relationship between bronchial histamine reactivity and atopic status. Clin Allergy 1976; 6: 373-381.

41. Martinez FD, Morgan WJ, Wright AL, Holberg CJ, Taussig LM, and the GHMA personnel. Diminished lung function as a predisposing factor for wheezing respiratory illness in infants. N Engl J Med 1988; 319: 1112-1117.

42. Martinez FD, Wright AL, Taussig LM, Holberg CJ, Halonen M, Morgan WJ and the GHMA. Asthma and wheezing in the first six years of life. $N$ Engl J Med 1995; 332: 133-138.

43. Speight ANP, Lee DA, Hey EN. Underdiagnosis and undertreatment of asthma in childhood. Br Med J 1983; 286: $1253-1256$. 